\title{
ATIVIDADE DE EXTRATOS DE Arrabidaea chica (HUMB. \& BONPL.) VERLOT OBTIDOS POR PROCESSOS BIOTECNOLÓGICOS SOBRE A PROLIFERAÇÃO DE FIBROBLASTOS E CÉLULAS TUMORAIS HUMANAS
}

\author{
Denise Taffarello \\ Instituto de Ciências Biomédicas, Universidade de São Paulo, Av. Prof. Lineu Prestes, 1730, 05508-900 SP - SP / Centro \\ Pluridisciplinar de Pesquisa Química, Biológicas e Agrícolas, Universidade Estadual de Campinas, CP 6171, 13083-970 Campinas \\ - SP, Brasil \\ Michelle Pedroza Jorge, Ilza Maria de Oliveira Sousa, Marta Cristina Teixeira Duarte, Glyn Mara Figueira, Nubia de \\ Cassia Almeida Queiroz, Rodney Alexandre Ferreira Rodrigues, João Ernesto de Carvalho, Ana Lucia Tasca Ruiz Goes \\ e Mary Ann Foglio* \\ Centro Pluridisciplinar de Pesquisa Química, Biológicas e Agrícolas, Universidade Estadual de Campinas, CP 6171, 13083-970 \\ Campinas - SP, Brasil \\ José Manuel Riveros \\ Instituto de Química, Universidade de São Paulo, Av. Prof. Lineu Prestes, 748, 05508-900, SP - SP, Brasil \\ Marcos Nogueira Eberlin e Elaine Cristina Cabral \\ Instituto de Química, Universidade Estadual de Campinas, CP 6154, 13083-970 Campinas - SP, Brasil
}

Recebido em 14/9/12; aceito em 15/10/12; publicado na web em 20/2/13

\begin{abstract}
ACTIVITY OF Arrabidaea chica (HUMB. \& BONPL.) VERLOT EXTRACTS OBTAINED BY BIOTECHNOLOGICAL PROCESSES ON FIBROBLAST AND HUMAN TUMOR CELLS. Arrabidaea chica (H\&B) Verlot is a plant popularly known as Pariri and this species is a known source of anthocyanins, flavonoids and tannins. This report describes an approach involving enzymatic treatment prior to extraction procedures to enhance $A$ chica crude extract anticancer activity. Anticancer activity in human cancer cell lines in vitro using a $48 \mathrm{~h} \mathrm{SRB}$ cell viability assay was performed to determine growth inhibition and cytotoxic properties. The final extraction yield without enzyme treatment was higher (24.28\%) compared to the enzyme-treated material (19.03\%), with an enhanced aglycones anthocyanin ratio as determined by HPLC- DAD and LC-MS with direct infusion.
\end{abstract}

Keywords: Arrabidaea chica; xylanases; antiproliferative activity.

\section{INTRODUÇÃO}

A espécie Arrabidaea chica (Humb. \& Bonpl.) Verlot (Bignoniaceae), encontrada principalmente na Região Amazônica, é popularmente conhecida como crajiru, carajiru, pariri e chica. Quando as folhas são submetidas à fermentação com anileira (Indigofera spp) fornecem um corante vermelho-escuro ou vermelho-tijolo, isômero do ácido anísico, insolúvel em água, sendo utilizado pelos índios para pintura do corpo e utensílios. ${ }^{1,2} \mathrm{O}$ uso popular de $A$. chica na medicina foi descrito por Pio Correa para o tratamento de leucemia, diarreias sanguinolentas, banho de assento e enfermidades da pele. ${ }^{2,3}$ Estudos in vitro e in vivo demonstraram a capacidade cicatrizante do extrato bruto de $A$. chica, com o aumento da produção de fibroblasto, ação tripanocida in vitro e atividade antimicrobiana. ${ }^{4}$

Nas folhas de A. chica foi relatada a presença de (1) 6,7,3',4'-tetra-hidoxi-5-metoxiflavilio, (2) 6,7,3'-tri-hidroxi-5-metoxiflavilio e a carajurina (3), 6,7-di-hidroxi-5,4'-dimetoxiflavilio (Figura 1) além de fito-esterois, taninos, flavonoides identificados como 7,4'-di-hidroxi-5-metaxoxiflavona e 6,3',4'-tetra-hidroxi-5-metoxiflavona (carajuruflavona). ${ }^{5}$ Glicosilxantonas foram isoladas do caule de $A$. samydoides e apresentaram propriedades antioxidantes. ${ }^{6}$

A Biotecnologia é uma atividade baseada em conhecimentos multidisciplinares, que utiliza agentes biológicos para viabilizar a produção de medicamentos, como os antibióticos, bem como resolver problemas com a biorremediação. ${ }^{7}$

O enriquecimento da extração de pigmentos vermelhos pela incubação prévia do material vegetal na presença de xilanases, oriunda

*e-mail: foglioma@cpqba.unicamp.br

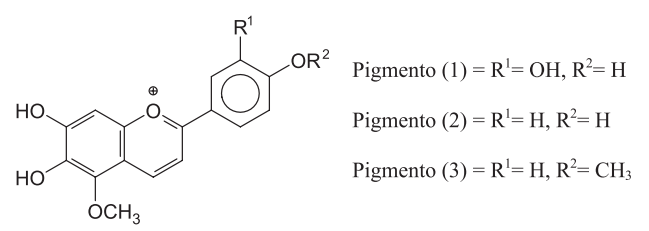

Figura 1. Estrutura química das 3 deoxiantocianinas isoladas de A. chica Verlot. (1) (6,7,3',4'-tetra-hidroxi-5-metoxiflavilio), (2) (6,7,4'-tri-hidroxi-5-metoxiflavilio) e carajurina (3) 6,7-di-hidroxi-5,4'-dimetoxiflavilio

de Bacillus sp, foi estudado por Kim e colaboradores. A incubação prévia com xilanases de Bacillus sp. aumentou o rendimento de extração dos pigmentos em $80 \%$ e reduziu o tempo de extração, além de apresentarem diversas atividades farmacológicas. ${ }^{8} \mathrm{O}$ interesse pela descoberta de novos antioxidantes seguros de fontes naturais tem aumentado, principalmente para prevenir o dano oxidativo às células vivas. O uso de antioxidantes sintéticos tem diminuído devido à suspeita de atividade como promotores de carcinogênese. ${ }^{9}$

O objetivo deste trabalho foi avaliar a influência do processo de fermentação enzimática de folhas de $A$. chica Verlot sobre a atividade farmacológica, empregando-se modelos de atividade anticâncer in vitro sobre células tumorais humanas, estímulo de crescimento de fibroblastos e ação antioxidante (DPPH).

\section{PARTE EXPERIMENTAL}

Material vegetal

Em 2005 foram introduzidos nove acessos da espécie Arrabidaea 
chica (Humb. \& Bonpl.) Verlot, oriundos de diferentes localidades do País (Paraná, Minas Gerais, Mato Grosso do Sul, Pará e Amazonas) no campo experimental do CPQBA/Unicamp, localizado no município de Paulínia, Estado de São Paulo. As exsicatas das plantas foram identificadas pela Dra. G. M. Figueira, estando depositadas no Herbário do CPQBA/Unicamp. Foram coletadas folhas mensalmente para realização de estudos da sazonalidade da espécie. A planta foi seca durante $48 \mathrm{~h}$ em estufa, marca Fabbe ${ }^{\circledR}$, a $40{ }^{\circ} \mathrm{C}$, com ventilação forçada, e posteriormente moída em moinho de facas com peneira de 40 mesh.

\section{Preparo do extrato sem tratamento enzimático}

Aproximadamente $100 \pm 10 \mathrm{mg}$ de folhas secas e moídas foram extraídas com metanol/ácido cítrico $0,3 \%(1: 5, \mathrm{v} / \mathrm{v})$ a temperatura ambiente, sob agitação constante em agitador oscilatório, em três ciclos de 1 h e 30 min. O extrato foi concentrado utilizando vácuo, protegido da luz. O extrato resultante foi submetido a tratamento por extração em fase sólida (EFS), para eliminação de clorofilas, para posterior análise por cromatografia líquida de alta eficiência.

\section{Padronização da extração enzimática}

Para padronização do processo foi realizado um planejamento experimental. As 17 amostras de A. chica secas e moídas foram submetidas a tratamento enzimático em diferentes condições, variando-se os tempos de incubação em 30, 60,90, 120 e 150 min e a concentração enzimática de 10 a $13 \mathrm{U} \mathrm{mL}^{-1}$ preparada a partir de caldo bruto de enzima xilanases com $180 \mathrm{U} \mathrm{mL}^{-1}$. $\mathrm{O} \mathrm{pH}$ das amostras foi mantido em 8,8 e a temperatura de incubação em $60^{\circ} \mathrm{C}$.

\section{Eliminação de clorofilas dos extratos brutos por extração em fase sólida (EFS)}

Os extratos produzidos com e sem tratamento enzimático foram submetidos à limpeza, para eliminação das clorofilas, utilizando-se cartucho C-18 marca Strata Phenomenex ${ }^{\circledR}$, com capacidade de $3 \mathrm{~mL}$, e $100 \mathrm{mg}$ de fase estacionária acoplada em um Manifold, marca J.T. Baker ${ }^{\circledR}$, sob vácuo, condicionado com $6 \mathrm{~mL}$ de solução ácida de $\mathrm{H}_{3} \mathrm{PO}_{4}$, em pH 2,0, descartando-se essa fração. Em seguida, dissolveu-se o extrato bruto em $2 \mathrm{~mL}$ de $\mathrm{MeOH}$ grau cromatográfico e adicionou-se ao cartucho $\mathrm{C} 18$ condicionado com água acidificada com $\mathrm{H}_{3} \mathrm{PO}_{4}$ e pH 2,0. Em seguida, eluiu-se o cartucho com aproximadamente $6 \mathrm{~mL}$ de $\mathrm{MeOH}$. A fração foi recolhida em balão volumétrico de $10 \mathrm{~mL}$. Completou-se o volume até $10 \mathrm{~mL}$, aferindo pelo menisco do balão volumétrico. A solução foi filtrada em filtro de $0,45 \mu \mathrm{m}$ marca Millepore ${ }^{\circledR}$ e armazenada em frasco âmbar para análise por CLAE.

\section{Condições cromatográficas}

As análises foram realizadas por cromatografia liquida de alta eficiência (CLAE) com bomba Shimadzu ${ }^{\circledR}$, LC 10 atm acoplada a detector de arranjo de diodos UV-Shimadzu ${ }^{\circledR}$ M10AVP e coluna C18 Gemine-Phenomenex ${ }^{\circledR}$, de $5 \mu \mathrm{m} 110 \mathrm{~A}^{\circ}(250$ x 4,6 mm x $5 \mu \mathrm{m})$. As condições cromatográficas e gradiente da fase móvel foram de dois solventes denominados $\mathrm{A}\left(\mathrm{H}_{2} \mathrm{O}+\mathrm{H}_{3} \mathrm{PO}_{4} ; \mathrm{pH} 2,0 \pm 0,10\right)$ e B (metanol). Do tempo 0 até 5 min utilizaram-se $55 \%$ de A e $45 \%$ de B. Na faixa de 5,1 até 20 min diminuiu-se para $10 \%$ da mistura A e $90 \%$ de metanol. De 20-30 min utilizou-se exclusivamente metanol. A partir de 30 min retomou-se o primeiro gradiente. $O$ volume de injeção foi de $20 \mu \mathrm{L}$, vazão de fluxo $1 \mathrm{~mL} \mathrm{~min}^{-1}$, comprimento de onda $470 \mathrm{~nm}$, utilizou-se forno CTO-10ASVP a $35^{\circ} \mathrm{C}$ e software Class VP- $5{ }^{\circledR}$. Os tempos de retenção dos compostos foram (1) 6,7,3', ,4'-tetra-hidroxi-5-metoxiflavilio) em 7,0-7,5 min; (2) 6,7,4'-tri-hidoxi-5-metoxiflavilio em 10,0-10,8 min e (3) carajurina 6,7-di-hidroxi-5,4'-dimetoxiflavilio em 17,0-17,9 $\mathrm{min}$.

\section{Avaliação da precisão da extração enzimática}

A precisão foi determinada através do teste de repetitividade das extrações com tratamento enzimático, utilizando mesmo método, mesmo analista, mesmo equipamento e laboratório, analisando 6 amostras, conforme resolução da ANVISA. ${ }^{10}$ A precisão intermediária foi realizada utilizando mesmo método, número de amostra, equipamento, em dias e analistas diferentes.

\section{Isolamento de 6,7-di-hidroxi-5,4'-dimetoxiflavilio (carajurina)}

A carajurina (3) presente no extrato bruto das folhas de A. chica foi purificada por coluna de resina Sephadex LH20 (Aldrich ${ }^{\circledR}$ ), $1 \mathrm{~g}$ de extrato bruto/g de Sephadex LH 20, eluente gradiente $\mathrm{H}_{2} \mathrm{O}: \mathrm{MeOH}$ TFA de 0,3 a $0,7 \%$. As frações foram monitoradas por cromatografia em camada delgada.

\section{Preparação de amostras para análises por IES-EM (+) e IES(+)-EM/EM}

Os extratos brutos obtidos com e sem tratamento enzimático (10 $\mathrm{mg}$ ) foram dissolvidos em $1 \mathrm{~mL}$ de $\mathrm{MeOH} / \mathrm{H}_{2} 0 \mathrm{com} 7 \%$ de ácido fórmico. Posteriormente, $10 \mu \mathrm{L}$ de alíquota foram retirados e diluídos em $990 \mu \mathrm{L}$ do mesmo solvente.

As amostras foram injetadas por inserção direta no espectrômetro de massas com auxílio de uma bomba seringa (Havard Aparatus ${ }^{\circledR}$ ) com fluxo de $10 \mu \mathrm{L} \mathrm{min}{ }^{-1}$. O tempo total para aquisição de cada espectro foi fixado em $1 \mathrm{~min}$. Os espectros IES-EM bem como os de IES-EM/ EM foram obtidos no modo positivo através do equipamento QTof Micromass $^{\circledR}$ (Manchester, Reino Unido) de configuração de ESIQqTof. As condições de operação do equipamento foram: $2.5 \mathrm{kV}$ de voltagem do capilar, $100^{\circ} \mathrm{C}$ de temperatura da fonte, temperatura de dessolvatação de $100{ }^{\circ} \mathrm{C}$ e voltagem do cone de $20 \mathrm{~V}$. Os espectros de full scan foram adquiridos na faixa de $m / z, 50$ a 1000 .

\section{Atividade farmacológica}

A avaliação das atividades antiproliferativa, o estímulo de crescimento e produção de fibroblastos in vitro e atividade antioxidante foram realizadas em todos os extratos obtidos durante o estudo de sazonalidade, permitindo assim estabelecer um perfil químico com relação aos efeitos farmacológicos observados.

\section{Teste de atividade antiproliferativa em cultura de células tumorais humanas}

Para os ensaios de atividade antiproliferativa in vitro, foram utilizadas 9 linhagens de células tumorais humanas: MCF-7 (mama), NCI-ADR/RES (ovário com fenótipo de resistência a múltiplas drogas), UACC-62 (melanoma), NCI-H460 (pulmão), PC-3 (próstata), HT29 (cólon), OVCAR-03 (ovário), 786-0 (rim) e K562 (leucemia). Estas linhagens foram cedidas pelo Instituto Nacional do Câncer (NCI/EUA), cultivadas em meio RPMI 1640, suplementado com 5\% de soro fetal bovino inativado (SFB), em atmosfera de $5 \%$ de $\mathrm{CO}_{2}$ a $37^{\circ} \mathrm{C}$ e ambiente úmido.

Uma mistura de penicilina e estreptomicina $\left(1 \mu \mathrm{g} \mathrm{mL}^{-1}: 1 \mathrm{UI} \mathrm{mL}^{-1}\right)$ foi adicionada às culturas experimentais. Células tumorais humanas (100 $\mu \mathrm{L}$ de suspensão celular por compartimento, densidade de inoculação entre $3 \times 10^{4}$ e $\left.6,5 \times 10^{4} \mathrm{cel} \mathrm{mL}^{-1}\right)$ foram expostas a diferentes concentrações das amostras em DMSO/RPMI/SFB 5\% (0,25; 2,$5 ; 25$ 
e $250 \mu \mathrm{g} \mathrm{mL}^{-1}$ ) e incubadas a $37{ }^{\circ} \mathrm{C}$ e $5 \%$ de $\mathrm{CO}_{2}$, em ambiente úmido, por $48 \mathrm{~h}$. Após esse período, as células foram fixadas com ácido tricloroacético $50 \%$. O conteúdo proteico celular foi determinado através da quantificação por espectrofotometria medida a $540 \mathrm{~nm}$, usando-se o teste de sulforrodamina B. ${ }^{11} \mathrm{~A}$ partir da curva de proliferação celular em função da concentração de amostra, calculou-se a concentração efetiva ITC (concentração que produz inibição total do crescimento) através de regressão não linear usando o software Origin $7.5^{\circledR}$ (OriginLab Corporation). ${ }^{12}$

\section{Estímulo de crescimento de fibroblasto in vitro}

A avaliação dos extratos brutos de $A$. chica (com e sem fermentação) foi realizada em fibroblastos de camundongos, linhagem 3T3, seguindo-se o protocolo descrito por Jorge et al.. ${ }^{4}$

\section{Atividade sequestrante de radicais livres DPPH}

Os extratos brutos de A. chica (com e sem fermentação) foram avaliados quanto a sua capacidade de sequestrar radicais livres DPPH, utilizando-se a técnica de microplaca. ${ }^{4}$

\section{RESULTADOS E DISCUSSÃO}

Visando a padronização da matéria-prima e exploração sustentável da espécie Arrabidaea chica Verlot, foi realizado estudo no CPQBA-UNICAMP (Centro de Pesquisas Químicas, Biológicas e Agrícolas da Universidade Estadual de Campinas) identificando marcadores microssatélites para caracterização genética de exemplares disponíveis no banco de germosplasma. Os espectros de IES(+)-EM gerados para as amostras dos diferentes acessos de $A$. chica, cultivados sob as mesmas condições, demonstraram que os acessos 3 e
5, oriundos do Paraná, apresentaram carajiruna abaixo do limite de detecção do equipamento, comparados aos outros acessos (Figura $2 \mathrm{a}$ e b). A partir desse estudo foi selecionado o acesso 6, oriundo de Manaus (exsicata 1865), para dar continuidade com o estudo, pois foi o acesso que apresentou maior teor das agliconas carajiruna e carajurona. ${ }^{4,13} \mathrm{O}$ estudo da variação sazonal da espécie foi realizado com e sem tratamento enzimático, coletando-se as folhas mensalmente de janeiro de 2007 a janeiro de $2008 .{ }^{14}$

A partir dos dados gerados pelo planejamento experimental foi estabelecido que as amostras fermentadas previamente ao processo de extração seriam produzidas utilizando $1,0 \mathrm{~g}$ de folhas de $A$. chica. Adicionaram-se 10,0 mL de tampão Tris $\left(\mathrm{pH} \mathrm{8,0),} 10 \mathrm{U} \mathrm{mL}^{-1} \mathrm{de}\right.$ xilanase, submetidas à agitação oscilatória de $80 \mathrm{rpm}$, à temperatura de $45{ }^{\circ} \mathrm{C}$ por $2 \mathrm{~h}$. O material vegetal fermentado foi posteriormente extraído à temperatura ambiente, sob agitação oscilatória, em solução de metanol/ácido cítrico 0,3\%, obtendo-se 33,2\% de rendimento.

Os extratos obtidos com e sem tratamento enzimático foram avaliados por CLAE DAD e analisados por IES (+)-EM, monitorando-se os componentes com razão $m / z, 285,299$ e 301 correspondentes às agliconas e os antocianosídeos majoritários com razão $m / z$. 463 e 477 (Figura 2).

A influência do processo de fermentação na atividade biológica de A. chica foi avaliada por comparação com o extrato sem tratamento. Os resultados demonstraram que a antocianidina 6,7-di-hidroxi-5,4'-dimetoxiflavilio teve variação significativa na sua concentração relativa (de 11,6 $\pm 0,2 \%$ para $16,00 \pm 0,05 \%$ ) após 60 min de tratamento prévio das folhas de $A$. chica com a mistura de xilanases. As outras duas antocianidinas (6,7,3,4'-tetra-hidoxi-5-metoxiflavilio e 6,7,4'-tri-hidroxi-5-metoxiflavilio) não sofreram alterações significativas após processo de fermentação das folhas. ${ }^{15}$ Contatou-se que o processo de hidrolise enzimático favoreceu o aumento do rendimento global da carajiruna (Figura 3).

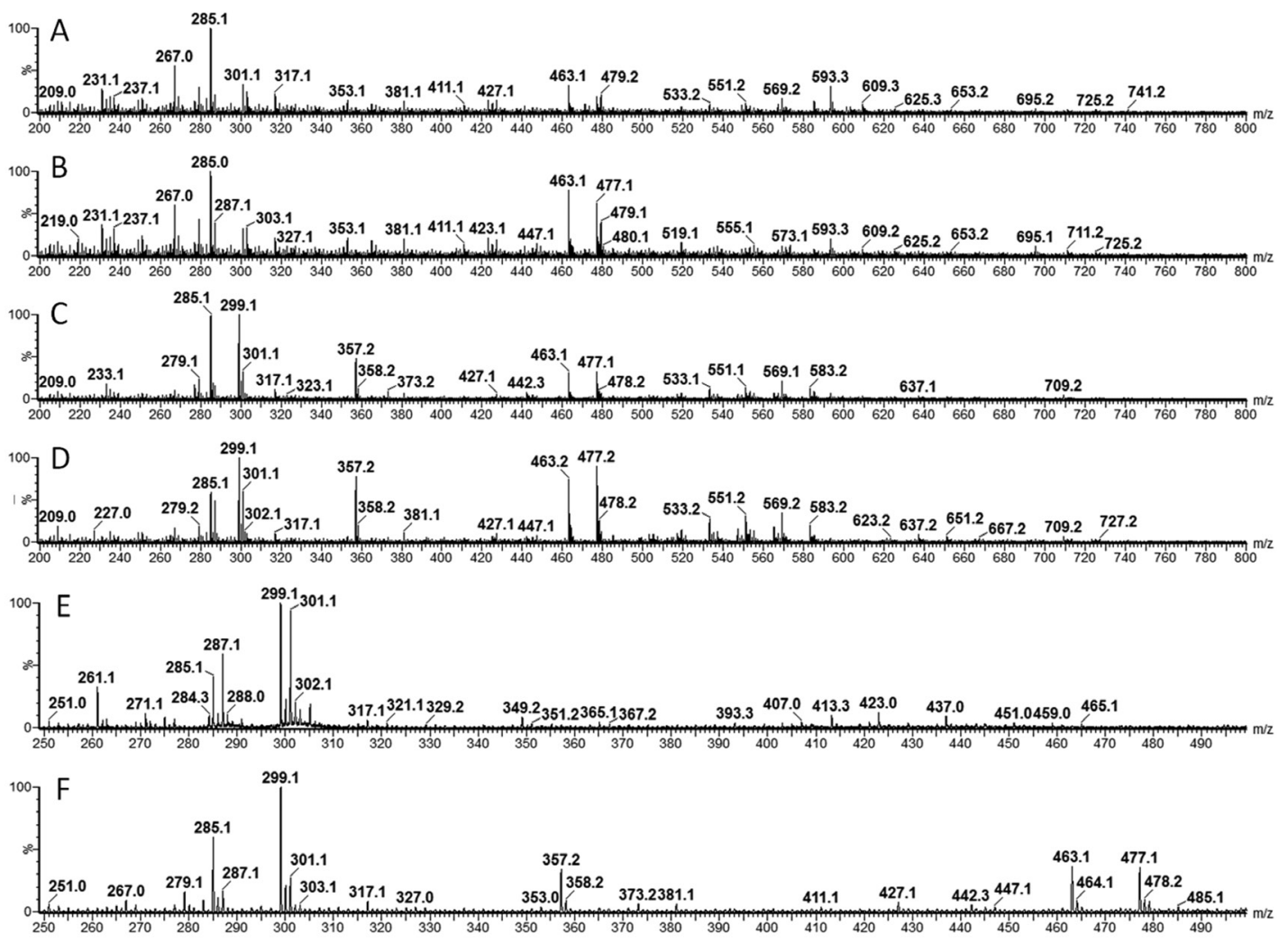

Figura 2. Espectros de IES(+)-EM obtidos para as amostras denominadas: A) acesso 3, B) acesso 5, C) acesso 6, D) acesso 9, E) acesso 6 sem tratamento enzimático e F) acesso 6 com tratamento enzimático 

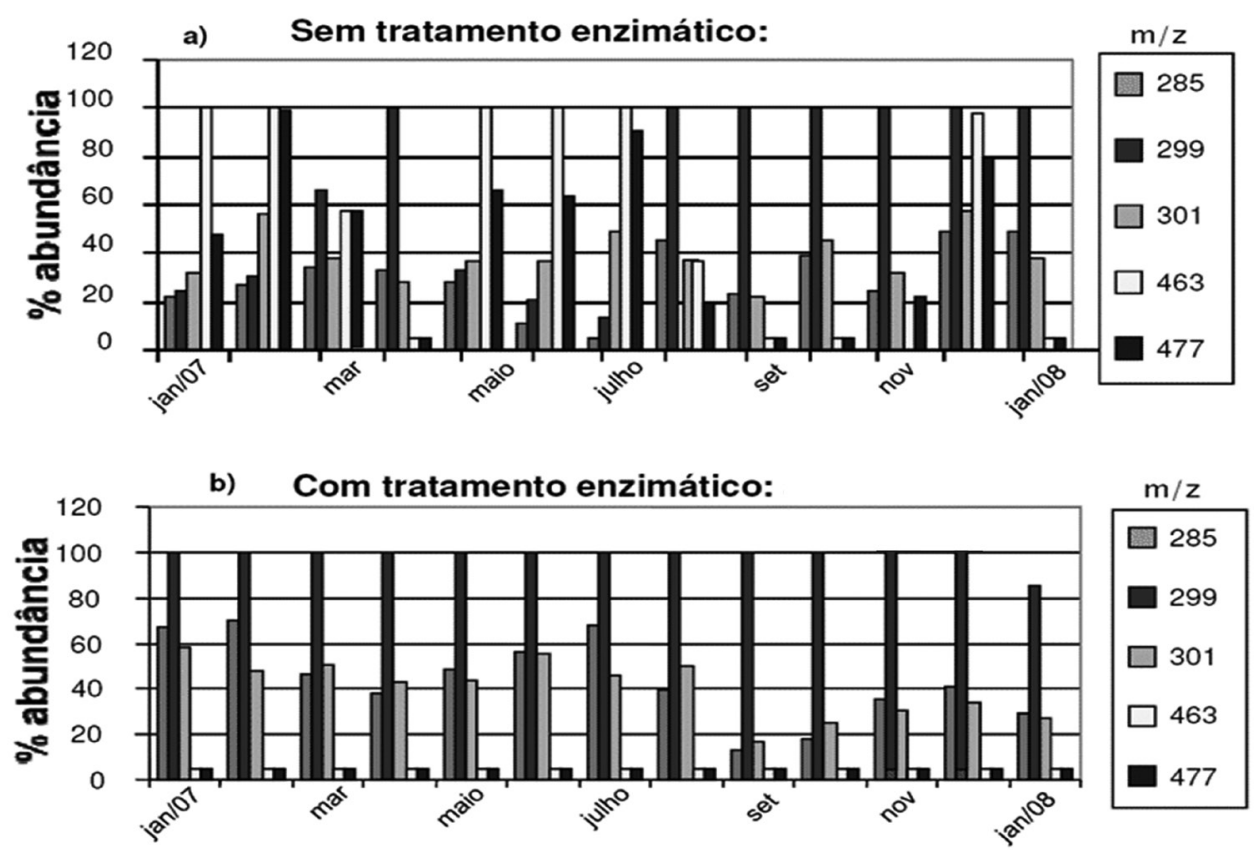

Figura 3. Intensidades relativas das antocianinas de m/z 285, 299, 301, 463 e 477 detectadas por IES(+)-EM para as amostras sazonais extraídas: a) sem tratamento prévio com xilanases e b) com tratamento prévio com xilanases, por $2 \mathrm{~h}$ a $40^{\circ} \mathrm{C}$

Através dos perfis avaliados por IES (+)-EM, observou-se que nos extratos obtidos sem tratamento enzimático, as intensidades dos íons referentes às agliconas e aos glicosídeos apresentaram variação sazonal ao longo do ano.

Apesar dos rendimentos médios das duas extrações terem sido análogos $(36 \pm 3 \%$ para sem tratamento e $33 \pm 2 \%$ com tratamento enzimático), o perfil químico observado apontou que houve um enriquecimento no conteúdo de antocianidinas nos extratos obtidos após o processo de fermentação das folhas (Figura 2e e f).

Através do ensaio de indução de crescimento celular verificou-se que os extratos brutos obtidos das folhas de A. chica sem tratamento prévio com xilanases estimularam o crescimento de fibroblastos da linhagem 3T3, nas concentrações de 0,$25 ; 2,5$ e $25 \mu \mathrm{g} \mathrm{mL}^{-1}$, sendo que a melhor atividade foi observada para os meses de janeiro a junho. Por outro lado, os extratos obtidos após o tratamento enzimático diminuíram a viabilidade celular, com exceção dos meses de janeiro e fevereiro que apresentaram crescimento moderado de fibroblastos.

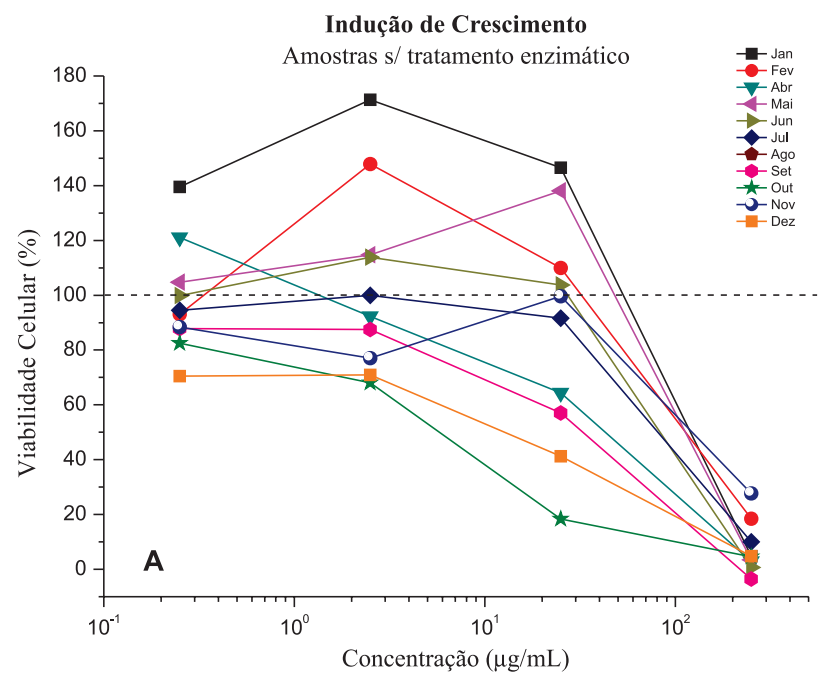

Todos os extratos diminuíram a concentração efetiva ITC celular em $250 \mu \mathrm{g} \mathrm{mL}^{-1}$ (Figura 4).

A comparação desses resultados com o perfil químico (Figura 2) sugeriu que a indução de crescimento de fibroblastos e, consequentemente, a ação cicatrizante dos extratos pode estar relacionada à presença das antocianinas, uma vez que os extratos ricos em antocianidinas (agliconas) não estimularam o crescimento celular (Figura 3).

O composto com íon $\mathrm{m} / \mathrm{z}, 463$ apresentou maior concentração nos meses de janeiro, fevereiro e maio de 2007 para as amostras sem tratamento enzimático, apresentando maior crescimento dos fibroblastos, sugerindo que esse componente deve estar envolvido com essa atividade. Já a análise dos extratos obtidos após o tratamento enzimático das folhas demonstrou uma redução significativa na concentração desse composto e, consequentemente, um menor crescimento de fibroblastos. O estudo do perfil químico por IES(+)-EM sugeriu ainda que outros compostos glicosilados podem estar envolvidos no mecanismo de estímulo, visto que os extratos produzidos

Figura 4. Efeito estimulante do extrato de A. chica em fibroblastos humanos. A) Extratos que não foram submetidos ao tratamento com xilanases de B. pumilus previamente à extração. B) Extratos submetidos ao tratamento enzimático 
Tabela 1. ITC $\left(\mu \mathrm{g} \mathrm{mL}^{-1}\right)$ : Inibição total de crescimento (Total Growth Inhibition) - concentração de extrato de A. chica necessária para que não ocorra crescimento celular

\begin{tabular}{|c|c|c|c|c|c|c|c|c|c|}
\hline & $\mathrm{U}$ & M & A & 7 & 4 & $\mathrm{P}$ & $\mathrm{O}$ & $\mathrm{H}$ & K \\
\hline Doxo & 0,31 & 1,70 & $>25$ & $>25$ & $>25$ & 1,07 & $>25$ & $>25$ & $>25$ \\
\hline jan/07 I & $>250$ & $>250$ & $>250$ & $>250$ & $>250$ & $>250$ & 0,85 & $>250$ & $>250$ \\
\hline jan/07 II & $>250$ & 39,9 & 153,4 & 190,1 & 66,8 & $>250$ & 1,6 & 194,7 & $>250$ \\
\hline fev/07 I & $>250$ & $>250$ & 250 & $>250$ & $>250$ & $>250$ & 250 & 250 & $>250$ \\
\hline fev/07 II & 27,1 & 46,5 & 48,3 & 72,4 & 130,0 & 35,3 & $>250$ & $>250$ & $>250$ \\
\hline mar/07 I & 78,7 & $>250$ & $>250$ & 169,8 & $>250$ & $>250$ & $>250$ & $>250$ & $>250$ \\
\hline mar/07 II & 36,8 & 41,9 & 37,7 & 157,7 & $>250$ & 34,2 & $>250$ & $>250$ & $>250$ \\
\hline abr/07 I & 16,8 & $>250$ & $>250$ & 130,1 & $>250$ & $>250$ & $>250$ & $>250$ & $>250$ \\
\hline abr/07 II & $\mathbf{5 0 , 9}$ & 80,5 & $>250$ & $>250$ & $>250$ & $>250$ & $>250$ & $>250$ & $>250$ \\
\hline mai/07 I & $>250$ & $>250$ & 79,87 & $>250$ & $>250$ & 43,92 & $>250$ & $>250$ & 27,6 \\
\hline mai/07 II & 8,7 & 35,8 & 81,1 & $>250$ & $>250$ & 71,5 & 50,2 & 90,9 & 11,1 \\
\hline jun/07 I & $>250$ & $>250$ & $>250$ & $>250$ & $>250$ & 187,2 & $>250$ & $>250$ & 2,59 \\
\hline jun/07 II & 7,4 & 37,5 & 66,7 & $>250$ & $>250$ & 108,5 & 45,5 & 95,9 & 25,6 \\
\hline jul/07 I & $>250$ & $>250$ & $>250$ & $>250$ & $>250$ & $>250$ & $>250$ & $>250$ & $>250$ \\
\hline jul/07 II & 62,7 & 73,3 & $\mathbf{0 , 8 8}$ & 137,2 & $>250$ & $>250$ & 47,6 & 110,8 & $>250$ \\
\hline ago/07 I & 65,4 & $>250$ & 63,8 & 250 & $>250$ & $>250$ & $>250$ & $>250$ & $>250$ \\
\hline ago/07 II & 125,3 & 45,5 & 2,6 & $>250$ & $>250$ & $>250$ & 81,5 & 104,5 & $>250$ \\
\hline set/07 I & 81,3 & 250 & 35,2 & 79,9 & $>250$ & $>250$ & $>250$ & $>250$ & $>250$ \\
\hline set/07II & 124,5 & $>250$ & $>250$ & 40,2 & $>250$ & $>250$ & $>250$ & $>250$ & $>250$ \\
\hline out/07 I & $>250$ & 43,7 & 73,9 & $>250$ & 63,8 & $>250$ & $>250$ & $>250$ & $>250$ \\
\hline out/07 II & 38,9 & 250 & $>250$ & $>250$ & 102,7 & $>250$ & 177,8 & $>250$ & $>250$ \\
\hline nov/07 I & $>250$ & $>250$ & $>250$ & $>250$ & $>250$ & $>250$ & 65,4 & $>250$ & $>250$ \\
\hline nov/07 II & 13,6 & 250 & $>250$ & $>250$ & 98,3 & $>250$ & 1,9 & $>250$ & $>250$ \\
\hline $\mathrm{dez} / 07 \mathrm{I}$ & 40,3 & 171,0 & $>250$ & $>250$ & 78,4 & 37,4 & 25,8 & 250 & $>250$ \\
\hline dez/07 II & $>250$ & $>250$ & $>250$ & $>250$ & $>250$ & $>250$ & $>250$ & $>250$ & $>250$ \\
\hline jan/08 I & $>250$ & 31,1 & $>250$ & $>250$ & $>250$ & $>250$ & $>250$ & $>250$ & $>250$ \\
\hline jan/08 II & $>250$ & $>250$ & $>250$ & $>250$ & $>250$ & $>250$ & $>250$ & $>250$ & $>250$ \\
\hline
\end{tabular}

$\mathrm{I}=\mathrm{EB}$ não tratado com xilanases; $\mathrm{II}=\mathrm{EB}$ tratado com xilanases; $\mathrm{U}=\mathrm{UACC}-62, \mathrm{M}=\mathrm{MCF}-7, \mathrm{~A}=\mathrm{NCI}-\mathrm{ADR} / \mathrm{RES}, 7$ = 786-0, 4 = NCI-H460, P = PC-3, O = OVCAR-3, H = HT-29, K = K562.

a partir das folhas coletadas nos meses de maio, junho e julho de 2007 apresentaram perfil químico semelhante quanto à presença do composto $\mathrm{m} / \mathrm{z} 477$, porém não estimularam de maneira semelhante o crescimento dos fibroblastos 3T3 (Figura 4).

Estudos farmacológicos destacam o alto poder antioxidante das antocianinas em doenças metabólicas, ${ }^{16}$ dentre as quais podemos destacar atividade anti-inflamatória e anticâncer. ${ }^{17}$ Neste contexto, a influência da variação na proporção relativa das antocianidinas nos extratos de $A$. chica, preparados com e sem tratamento enzimático prévio, a partir de folhas coletadas durante os 13 meses, frente à atividade antiproliferativa in vitro foi avaliada em um painel de 9 linhagens de células tumorais humanas [MCF-7 (mama), NCI-ADR/ RES (ovário com fenótipo de resistência a múltiplas drogas), UACC62 (melanoma), NCI-H460 (pulmão), PC-3 (próstata), HT29 (cólon), OVCAR-03 (ovário), 786-0 (rim) e K562 (leucemia)] enquanto a atividade antioxidante potencial foi observada através do ensaio de DPPH.

A atividade antiproliferativa foi expressa através de valores de inibição total de crescimento ITC (TGI - Total Growth Inhibition), que representa a concentração de amostra necessária para que não ocorra crescimento celular (efeito citostático máximo). ${ }^{18}$ Os resultados obtidos para os diversos extratos de $A$. chica estão resumidos na Tabela 1.

Fouche et al. ${ }^{19}$ descreveram parâmetros para avaliação do potencial antiproliferativo com base nos valores médios de ITC. Assim, para ser ativo um extrato precisa apresentar média de ITC $\leq 50 \mu \mathrm{g}$ $\mathrm{mL}^{-1}$. Por este parâmetro, todos os extratos avaliados foram inativos. Porém, foi interessante observar que os extratos resultantes de amostras submetidas à hidrolise enzimática das folhas, previamente ao processo de extração, apresentaram atividade antiproliferativa in vitro (amostras coletadas nos meses de janeiro, fevereiro, março, abril, maio, junho, julho e agosto). Os extratos obtidos nos meses de maio e de junho de 2007 apresentaram efeito citostático para a linhagem UACC-62 (melanoma) com valores de ITC iguais a 8,7 e 7,4 $\mu \mathrm{g} \mathrm{mL}^{-1}$, respectivamente, comparado ao valor acima de $250 \mu \mathrm{g} \mathrm{mL}^{-1}$ para as mesmas amostras sem o tratamento enzimático.

Em relação à atividade antioxidante, o ensaio de DPPH permitiu avaliar a capacidade de sequestrar radicais livres. Neste trabalho observamos uma moderada atividade antioxidante para os extratos brutos de A. chica sem tratamento prévio (T2I) com um aumento da atividade para os extratos das folhas tratadas previamente com xilanases de B. pumilus (T3II) (Tabela 2), indicando que tal atividade foi favorecida pela presença de antocianidinas. Após o processo de fermentação da planta ocorreu a liberação das agliconas, aumentando a atividade antioxidante, resultado corroborado pelos estudos de Cai et al. ${ }^{20}$ que relataram que a glicosilação dos flavonoides diminui sua capacidade antioxidante quando comparada com suas agliconas correspondentes (Tabela 2).

\section{CONCLUSÃO}

Através do monitoramento por IES(+)-EM estabeleceu-se o perfil de antocianosídeos e suas respectivas agliconas, de plantas de $A$. chica provenientes de diferentes origens geográficas (acessos), permitindo a seleção de uma variedade com características específicas para produção de extratos com atividade farmacológica. 
Tabela 2. Efeito antioxidante dos extratos de folhas de A. chica, coletadas ao longo do ano, não tratadas com xilanases (T2I) e tratadas com xilanases de B. pumilus (T3II) em ensaio com DPPH

\begin{tabular}{|c|c|c|c|}
\hline Amostra & $\mathrm{EC}_{50}\left(\mu \mathrm{g} \mathrm{mL} L^{-1}\right)$ & $\mathrm{T}_{\mathrm{EC} 50}(\min )$ & $\mathrm{AE}^{*}$ \\
\hline Trolox & $5,40 \pm 0,58$ & 0,1 & $1,9 \pm 0,2$ \\
\hline jan/07 T3I & $75,96 \pm 2,13$ & 0,1 & $0,132 \pm 0,004$ \\
\hline fev/07 T2I & $234,29 \pm 77,76$ & 0,1 & $0,06 \pm 0,02$ \\
\hline fev/07 T3I & $75,43 \pm 4,42$ & 0,1 & $0,133 \pm 0,008$ \\
\hline $\mathrm{mar} / 07 \mathrm{~T} 2 \mathrm{I}$ & $97,90 \pm 7,41$ & 0,1 & $0,103 \pm 0,007$ \\
\hline mar/07 T3I & $42,44 \pm 0,58$ & 0,1 & $0,236 \pm 0,003$ \\
\hline $\mathrm{abr} / 07 \mathrm{~T} 2 \mathrm{I}$ & $142,08 \pm 8,76$ & 0,1 & $0,071 \pm 0,004$ \\
\hline abr/07 T3I & $83,25 \pm 12,57$ & 5 & $0,0025 \pm 0,0003$ \\
\hline mai/07 T2I & $121,92 \pm 13,70$ & 0,1 & $0,084 \pm 0,009$ \\
\hline mai/07 T3I & $45,00 \pm 0,75$ & 0,1 & $0,222 \pm 0,004$ \\
\hline jun/07 T2I & $138,01 \pm 4,22$ & 0,1 & $0,073 \pm 0,002$ \\
\hline jun/07 T3I & $43,27 \pm 3,48$ & 0,1 & $0,23 \pm 0,02$ \\
\hline jul/07 T2I & $41,4783 \pm 1,46$ & 5 & $0,0048 \pm 0,0002$ \\
\hline jul/07 T3I & $52,70 \pm 10,64$ & 0,1 & $0,21 \pm 0,05$ \\
\hline ago/07 T2I & $67,55 \pm 3,52$ & 0,1 & $0,149 \pm 0,008$ \\
\hline ago/07 T3I & $204,42 \pm 11,96$ & 0,1 & $0,049 \pm 0,003$ \\
\hline set/07 T2I & $94,36 \pm 8,60$ & 0,1 & $0,11 \pm 0,01$ \\
\hline set/07T3I & $357,54 \pm 11,85$ & 5 & $0,000561 \pm 0,00002$ \\
\hline $\mathrm{jan} / 07 \mathrm{~T} 2 \mathrm{I}$ & $133,43 \pm 7,48$ & 0,1 & $0,075 \pm 0,004$ \\
\hline out/07 T2I & $44,47 \pm 2,91$ & 0,1 & $0,23 \pm 0,02$ \\
\hline out/07 T3I & $60,05 \pm 8,69$ & 0,1 & $\mathbf{0 , 1 7} \pm \mathbf{0 , 0 3}$ \\
\hline nov/07 T2I & $61,09 \pm 1,39$ & 5 & $0,00328 \pm 0,00007$ \\
\hline nov/07 T3I & $30,79 \pm 1,14$ & 0,1 & $\mathbf{0 , 3 3} \pm \mathbf{0 , 0 1}$ \\
\hline dez/07 T2I & $28,86 \pm 1,86$ & 0,1 & $0,35 \pm 0,02$ \\
\hline dez/07 T3I & $63,18 \pm 2,71$ & 0,1 & $\mathbf{0 , 1 5 8} \pm \mathbf{0 , 0 0 7}$ \\
\hline $\mathrm{jan} / 08 \mathrm{~T} 2 \mathrm{I}$ & $29,26 \pm 3,89$ & 0,1 & $0,35 \pm 0,05$ \\
\hline jan/08 T3I & $83,40 \pm 7,54$ & 0,1 & $0,12 \pm 0,01$ \\
\hline
\end{tabular}

$\mathrm{EC}_{50}$ : concentração necessária para reduzir em $50 \%$ a concentração inicial de $\mathrm{DPPH}, \mathrm{T}_{\mathrm{EC} 50}$ : tempo necessário para atingir a $\mathrm{EC}_{50}$, $\mathrm{AE}$ : Eficiência Antirradicalar $\left(\mathrm{AE}=1 /\left(\mathrm{EC}_{50} * \mathrm{~T}_{\mathrm{EC} 50}\right)\right)$.

Os resultados sugerem que parâmetros como processamento pós-colheita e método de extração influenciam a composição química e, consequentemente, a atividade farmacológica observada para o produto final.

Estudos de biologia molecular utilizando marcadores microssatélites permitiram estabelecer algumas das características genotípicas importantes para padronização dos insumos para produzir extratos com os efeitos farmacológicos descritos neste estudo. ${ }^{14}$

Este estudo contribuiu com dados relevantes para a padronização da matéria-prima vegetal, contribuindo para a compreensão dos parâmetros necessários ao produto para atender as necessidades de eficácia, segurança e reprodutibilidade imprescindíveis ao desenvolvimento de medicamentos fitoterápicos.

\section{AGRADECIMENTOS}

FAPESP, CAPES, CNPq.

\section{REFERÊNCIAS}

1. Chapman, E.; Perkin, A. G.; Robinson, R.; J. Chem. Soc. 1927, 49, 3015.

2. Corrêa, M. P.; Dicionário das plantas úteis do Brasil e das exóticas cultivadas, Re-edição, Imprensa Nacional: Rio de Janeiro, 1984.

3. Lorenzi, H.; Matos, F. J. A.; Plantas Medicinais no Brasil nativas e exóticas, $1^{\text {a }}$ ed., Instituto Platarum: São Paulo, 2002.

4. Jorge, M. P.; Madjarof, C.; Ruiz, A. L. T. G.; Fernandes, A. T.; Rodrigues, R. A. F.; Sousa, I. M. O.; Foglio, M. A.; Carvalho, J. E.; J. Ethnopharmacol. 2008, 118, 361; Barbosa, W. L. R.; Nascimento Pinto, L.; Quignard, E.; Vieira, J. M. S.; Silva Jr., J. O. C.; Albuquerque, S.; Rev. Bras. Farmacogn. 2010, 18, 544; Höfling, J. F.; Anibal, P. C.; Obando-Pereda, G. A.; Peixoto, I. A. T.; Furletti, V. F.; Foglio, M. A.; Gonçalves, R. B.; Braz. J. Biol. 2010, 70, 1065.

5. Castaneda-Ovando, A.; Pacheco-Hernandez, M. L.; Paez-Hernandez, M. E.; Rodriguez, J. A.; Galan-Vidal, C. A.; Food Chem. 2009, 113, 859.

6. Scogin, R.; Biochem. Syst. Ecol. 1927, 8, 273; Harborne, J. B.; Phytochemistry 1967, 6, 1643; Harborne, J. B.; Williams, C. A.; Nat. Prod. Rep. 2001, 18, 310; Takemura, O. S.; Iinuma, M.; Tosa, H.; Miguel, O. G.; Moreira, E. A.; Nozawa, Y.; Phytochemistry 1995, 38, 1299; Zorn, B.; García-Pineres, A. J.; Castro, V.; Murillo, R.; Mora, G.; Merfort, I.; Phytochemistry 2001, 56, 831; Devia, B.; Llabres, G.; Wouters, J.; Dupont, L.; Escribano-Bailon, M. T.; De Pascual-Teresa, S.; Angenot, L.; Tits, M.; Phytochem. Anal. 2002, 13, 63; Alcerito, T.; Barbo, F. E.; Negri, G.; Santos, D. Y. A. C.; Meda, C. I.; Young, M. C. M.; Chávez, D.; Blatt, C. T. T.; Biochem. Syst. Ecol. 2002, 30, 677; Pauletti, P. M.; Castro-Gamboa, I.; Silva, D. H. S.; Young, M. C. M.; Tomazela, D. M.; Eberlin, M. N.; Bolzani, V. S.; J. Nat.Prod. 2003, 66, 1384.

7. Março, P. H.; Poppi, R. J.; Scarminio I. S.; Quim. Nova 2008, 31, 1218.

8. Poorna, C. A.; Prema, P.; Biochem. Eng. J. 2006, 32, 106.

9. Kim, D. H.; Kim, J. H.; Bae, S. I.; Seo, J. H.; Oh, T. K.; Lee, C. H.; J. Agric. Food Chem. 2005, 53, 2541

10. Li, H.-B.; Wong, C.-C.; Cheng, K.-W.; Chen, F.; LWT - Food Sci. Technol. 2008, 2, 104.

11. Brasil, Agência Nacional de Vigilância Sanitária (ANVISA); Resolução RE nº 899, de 29/05/2003. Diário Oficial da União de 30/05/2003.

12. Monks, A.; Scudiero, D.; Skehan, P.; Shoemaker, R.; Paull, K.; Vistica, D.; Hose, C.; Langley, J.; Cronise, P.; Vaigro-Wolff, A.; Gray-Goodrich, M.; Campbell, H.; Mayo, J.; Boyd, M.; J. Nat. Cancer Inst. 1991, 83, 757.

13. Shoemaker, R. H.; Nat. Rev. Cancer 2006, 6, 813.

14. Figueira, G. M.; Ramelo, P. R.; Ogasawara, D. C.; Montanari, I.; Zucchi, M. I.; Cavallari, M. M.; Foglio, M. A.; Am. J. Bot. 2010, 98, 283.

15. Duarte, M. C. T.; Pellegrino, A. C. A.; Portugal, E. P.; Ponezi, A. N.; Franco, T. T.; Braz. J. Microbiol. 2001, 31, 90.

16. Taffarello, D.; Dissertação de Mestrado, Universidade de São Paulo, Brasil, 2008

17. Zafra-Stone, S.; Yasmin, T.; Bagchi, M.; Chatterjee, A.; Vinson, J. A.; Bagchi, D.; Mol. Nutr. Food Res. 2007, 51, 675.

18. Kong, J. M.; Chia, L. S.; Goh, N.-K.; Chia, T.-F.; Brouillard, R.; Phytochemistry 2003, 64, 923.

19. Fouche, G.; Cragg, G. M.; Pillay, P.; Kolesnikova, N.; Maharaj, V. J.; Senabe, J.; J. Ethnopharmacol. 2008, 119, 455.

20. Cai, Y.-Z.; Xing, J.; Sun, M.; Zhan, Z.-Q.; Corke, H.; J. Agric. Food Chem. 2005, 53, 9940. 